\title{
Acute Haemodialysis-induced Changes in Tissue Doppler Echocardiography Parameters
}

\author{
Saim Sağ ${ }^{1}$, Dilek Yeşilbursa ${ }^{1}$, Abdulmecit Yıldız², Kamil Dilek², Tunay Şentürk ${ }^{1}$, Osman Akın Serdar ${ }^{1}$, Ali Aydınlar ${ }^{1}$ \\ ${ }^{1}$ Department of Cardiology, Uludağ University Faculty of Medicine, Bursa, Turkey \\ ${ }^{2}$ Department of Nephrology, Uludağ University Faculty of Medicine, Bursa, Turkey
}

Background: Tissue Doppler imaging (TDI) is a method that determines the tissue motion and velocity within the myocardium.

Aims: To characterize acute haemodialysis (HD)-induced changes in TDI-derived indices for patients that have end-stage renal disease (ESRD).

Study Design: Cross sectional study.

Methods: Conventional echocardiography and TDI methods were applied to study ESRD patients $(n=58)$ before and after HD. Pulmonary venous flow, mitral inflow, and TDI signals of the lateral and septal mitral annulus were examined for the determination of altered left-ventricular diastolic filling parameters. Flow velocities from early- (E) and late-atrial (A) peak transmitral; peak pulmonary vein systolic (S) and diastolic (D); and myocardial peak systolic (Sm) and peak early $(\mathrm{Em})$ and late (Am) diastolic mitral annular velocities were also assessed for changes.
Results: Transmitral $\mathrm{E}$ and $\mathrm{A}$ velocities and the $\mathrm{E} / \mathrm{A}$ ratio decreased significantly after HD $(p<0.001)$. Pulmonary vein $S(p<0.001)$ and D $(p<0.001)$ velocities decreased, and $S / D$ ratios increased significantly $(p=0.027)$. HD led to a reduction in septal Em $(p<0.001)$, lateral Em $(p=0.006)$, and $A m(p<0.001)$ velocities. Contrary to the decreases in Em and Am, the Em/Am ratio remained unchanged.

Conclusion: A single HD session was associated with an acute deterioration in the diastolic parameters. Since the Em/Am ratio remained unchanged, we conclude that this index is a relatively loadindependent measure of diastolic function in HD patients.

(Balkan Med J 2014;31:239-43).

Key Words: Echocardiography, haemodialysis, left ventricular systolic and diastolic function, tissue Doppler imaging
Cardiovascular diseases are common in patients with endstage renal disease (ESRD) and are the main causes of morbidity and mortality (1-3). A large body of evidence has accrued indicating that a portion of this cardiovascular damage may be due to haemodialysis (HD) $(4,5)$. Notably, cardiovascular events contribute to increased death rates (10- to 20-fold) in HD patients compared to the general population, regardless of gender, race, and the general risk factors associated with heart disease (6). Short recurrent HD therapy is recognized to have a positive impact on haemodynamics, and approximately $20-30 \%$ can be convoluted by major intradialytic hypotension attacks (7). Previous studies have also shown that HD is known to induce haemodynamic instability through the development of subclinical myocardial ischemia, (8). Interestingly, sudden death appears to cause cardiovascular death in HD patients (9). There is evidence suggesting that cardiac arrhythmias are caused by abnormal ventricular morphology and function in this group of patients (10). Therefore, studying changes in cardiac functions induced by HD may be of significant clinical value.
Cardiac function is routinely measured using diagnostic imaging techniques. Echocardiography (ECHO) is a conventional method that can measure systolic and diastolic functions of the right ventricle (RV) and left ventricle (LV). However, most traditional ECHO parameters of LV and RV diastolic and systolic functions are affected by alterations in loading conditions and are therefore called load-dependent (11). In HD patients, loading influence is principal for the functional examination of the heart. Certainly, the alterations in volume status cause significant changes in preload and afterload and ultimately effect the LV diastolic function measurements (12-14). The use of newer Doppler techniques that can examine cardiac function independent of volume status, such as tissue Doppler imaging (TDI), may prove useful for early diagnosis $(12,13)$. TDI can adequately measure relaxation and contraction velocities from the myocardium and has been recommended as quantitative and relatively load-independent $(11,14)$. Throughout HD treatment, the intravascular volume of these patients is reduced a plausible group to investigate the role of acute preload 
reduction on TDI. Therefore, we designed the present study to assess the acute effects induced by a single HD session on traditional and TDI parameters in a patient cohort with ESRD.

\section{MATERIAL AND METHODS}

The study was developed and adapted within the guidelines and ethical principles defined in the Declaration of Helsinki. In addition, the following investigation was approved by an International Review Board. All patients approved and consented to participate in the study.

\section{Study design and participants}

Fifty-eight HD patients $(\mathrm{n}=58)$ (30 males and 28 females; mean age, $41.6 \pm 13.1$ years; and mean HD duration, $73.7 \pm 51.8$ months) with a history of ESRD in the absence of documented atherosclerosis or systemic pathologies (including malignancy, active infection, and inflammation) comprised our study. The ESRD aetiologies were as follows: primary hypertension in 15, chronic glomerulonephritis in 10, diabetes mellitus in 4, polycystic kidney disease in 2, nephrolithiasis in 11, and other causes in 16 patients.

Haemodialysis therapy was given for 3.5 to 4 hours, thrice weekly with highly tissue-compatible membranes. The dialysis used was composed of potassium $2.0 \mathrm{mmol} / \mathrm{L}$, sodium $140 \mathrm{mmol} / \mathrm{L}$, and calcium $1.5 \mathrm{mmol} / \mathrm{L}$. Clinical findings of overhydration were not present. In particular, patients did not have uncontrolled hypertension, dyspnoea, and oedema, or any signs of fluid retention according to the chest radiography. The use of cardiac drugs was recorded in all participants. Aspirin was used for 15 patients; ACE inhibitors for 6 patients; ARBs for 5 patients; beta-adrenergic blockers for 13 patients; calcium antagonists for 11 patients; diuretics for 4 patients; insulin for 4 patients; and statins for 8 patients. Fifty-four patients received erythropoietin. Body mass index (BMI) was assessed using the simple formula of the patient's weight $(\mathrm{kg})$ over their height $\left(\mathrm{m}^{2}\right)$. Blood analyses were calculated on a Hitachi 7350 Autoanalyser (Hitachi Ltd., Tokyo, Japan) utilizing kits available through a manufacturer.

\section{Echocardiography}

M-Mode, Two-dimensional (2-D), conventional-Doppler, and tissue Doppler ECHO analyses were done immediately before and after HD with the use of a Vivid 7 (General Electric, Horten, Norway) echocardiography machine in parallel with a transducer $(3.5 \mathrm{MHz})$. All echocardiographic data was calculated based on the American Society of Echocardiography Guidelines (15). Analysis of LV size, mass, fractional shortening (FS), ejection fraction (EF), and left atrial (LA) size and volume were determined by M-mode and 2-D echocardiography. To measure LV diastolic-filling parameter alter- ations, Doppler signals were recorded from the mitral inflow, PV inflow, and TDI of the mitral annulus. Early (E) and late atrial (A) peak transmitral flow velocities were measured from the mitral inflow. Peak PV systolic (S) and diastolic (D) flow velocities were obtained and calculated from the left upper PV inflow. The mitral and tricuspid annular planes were set vertical to the ultrasound beam and TDI signals were obtained. Pulsed TD sample volume $(5 \mathrm{~mm})$ was observed at the tricuspid annulus on the lateral side as well as the mitral annulus septal and lateral borders. Care was used to avoid Doppler inflow and background noise peaks. Both septal and lateral mitral annulus measurements were collected and peak Sm, peak $\mathrm{Em}$, late peak Am, and the $\mathrm{Em} / \mathrm{Am}$ ratio were determined for this site. All measurements were documented at a stroke rate of $100 \mathrm{~mm} / \mathrm{s}$. A minimum of three separate heartbeats was used to determine the mean calculations. ECHO data collected was subjected to a single blinded, independent bystander with no knowledge of the patient's identity, but aware of their preand post-HD status. Intraobserver variability was determined to be $0.3 \pm 0.7 \%$ for the TDI ECHO variables.

\section{Data analysis}

Continuous variables were calculated as the average \pm standard deviation. Nominal variables were reported as counts. A Student's $t$-test was performed on 'Within-group' comparisons. Multiple-linear regression analysis was performed on the fluctuations in ECHO measurements independent of the potential confounders. This analysis involved gender, age, BMI, blood pressure, creatinine, serum electrolytes, and ultrafiltration volume. Statistical analyses were performed utilizing Statistical Package for the Social Sciences (SPSS) 17.0 (SPSS Inc., Chicago, IL, USA). A $P$-value less than 0.05 was used a cutoff for statistical significance.

\section{RESULTS}

The pre- and post-HD measured values are shown in Table 1. BMI, systolic/diastolic and mean blood pressure, urea, creatinine, sodium, potassium, phosphorus, and calcium all decreased significantly following $\mathrm{HD}$ (all $\mathrm{p}$ values $<0.001$ ).

Haemodialysis-induced, two-dimensional, and M-mode echocardiographic parameter changes are reported in Table 2. We found no statistically significant post-HD alterations in LV systolic functions (ejection fraction and fractional shortening). In contrast, LV size and mass, stroke volume, cardiac output, and left atrial size and capacity decreased significantly following HD (all $\mathrm{p}$ values $<0.001$ ). HD-induced Doppler and TDI changes are reported in Table 3. Transmitral $\mathrm{E}$ and $\mathrm{A}$ velocities and $\mathrm{E} / \mathrm{A}$ ratios decreased significantly following $\mathrm{HD}(\mathrm{p}<0.001)$. Pulmonary vein $S(p<0.001)$ and $D(p<0.001)$ velocities decreased, while S/D ratios markedly elevated after HD treat- 
TABLE 1. General characteristics of patients with ESRD before and after $\mathrm{HD}$ treatment (mean $\pm \mathrm{SD})$

\begin{tabular}{lccc}
\hline & Before HD & After HD & p value \\
\hline Body mass index $\left(\mathrm{kg} / \mathrm{m}^{2}\right)$ & $24.4 \pm 4.5$ & $23.2 \pm 4.4$ & $<0.001$ \\
Systolic blood pressure $(\mathrm{mmHg})$ & $145 \pm 33$ & $127 \pm 28$ & $<0.001$ \\
Diastolic blood pressure (mmHg) & $84 \pm 18$ & $77 \pm 16$ & $<0.001$ \\
Urea $(\mathrm{mg} / \mathrm{dL})$ & $142 \pm 35$ & $37 \pm 14$ & $<0.001$ \\
Creatinine $(\mathrm{mg} / \mathrm{dL})$ & $9.8 \pm 1.9$ & $3.4 \pm 1.0$ & $<0.001$ \\
Serum sodium $(\mathrm{mEq} / \mathrm{L})$ & $140 \pm 2.2$ & $138 \pm 2.0$ & $<0.001$ \\
Serum potassium $(\mathrm{mEq} / \mathrm{L})$ & $5.0 \pm 0.6$ & $3.3 \pm 0.5$ & $<0.001$ \\
Serum phosphorus $(\mathrm{mg} / \mathrm{dL})$ & $5.4 \pm 1.3$ & $3.8 \pm 0.9$ & $<0.001$ \\
Serum calcium $(\mathrm{mg} / \mathrm{dL})$ & $8.9 \pm 0.7$ & $10.4 \pm 0.8$ & $<0.001$ \\
\hline
\end{tabular}

HD: haemodialysis; ESRD: end-stage renal disease; SD: standard deviation

TABLE 2. Two-dimensional and M-mode echocardiographic parameters of patients with ESRD pre- and post-HD therapy (mean \pm S.D.)

\begin{tabular}{lccc}
\hline & Before HD & After HD & p value \\
\hline LV end-diastolic diameter, mm & $47.5 \pm 5.8$ & $43.8 \pm 5.9$ & $<0.001$ \\
LV end-systolic diameter, mm & $31.6 \pm 5.4$ & $29.8 \pm 5.5$ & $<0.001$ \\
LV ejection fraction, \% & $69.2 \pm 7.6$ & $67.5 \pm 7.9$ & 0.07 \\
LV fractional shortening, \% & $33.1 \pm 5.5$ & $31.9 \pm 5.9$ & 0.08 \\
Stroke volume, mL & $75.5 \pm 26.3$ & $62.1 \pm 20.6$ & $<0.001$ \\
Cardiac output, L/min & $5.7 \pm 2.1$ & $5.0 \pm 1.8$ & $<0.001$ \\
LV mass index, g/m ${ }^{2}$ & $159 \pm 50$ & $150 \pm 46$ & $<0.001$ \\
LA diameter, mm & $38 \pm 5$ & $33 \pm 5$ & $<0.001$ \\
LA volume, $\mathrm{mL}$ & $51.5 \pm 17.2$ & $36.4 \pm 15.4$ & $<0.001$ \\
RA diameter, mm & $32.9 \pm 3.9$ & $29.6 \pm 3.7$ & $<0.001$ \\
\hline
\end{tabular}

HD: haemodialysis; ESRD: end-stage renal disease; LV: left ventricle; LA: left atrium

ment $(\mathrm{p}=0.027)$. Decreases in septal $\mathrm{Em}(\mathrm{p}<0.001)$, lateral Em $(\mathrm{p}=0.006)$, and Am $(\mathrm{p}<0.001)$ velocities were also observed after HD. Contrary to a decrease in Em and Am, the Em/Am ratio remained unchanged.

No statistically significant relationship was determined for the changes associated with $\mathrm{Em} / \mathrm{Am}$ ratio and gender, age, body mass index, ultrafiltration volume, mean blood pressure, creatinine, and electrolyte levels (Table 4).

\section{DISCUSSION}

This research investigation was performed to validate whether a single HD treatment creates substantial changes in ECHO and TDI parameters in chronic stable ESRD patients. The present study demonstrated three main results that should be considered. First, LV systolic function was not affected by preload reduction. Although LV stroke volume, cardiac output, end-systolic, and end-diastolic size decreased after a single HD session, ejection fraction and fractional shortening
TABLE 3. Conventional Doppler and TDI echocardiographic parameters from ESRD patients pre- and post-HD treatment (mean $\pm \mathrm{SD}$ )

\begin{tabular}{|c|c|c|c|}
\hline & Before HD & After HD & $\mathrm{p}$ value \\
\hline $\begin{array}{l}\text { E (Mitral inflow early } \\
\text { diastolic flow), } \mathrm{cm} / \mathrm{sn}\end{array}$ & $108 \pm 31$ & $75 \pm 25$ & $<0.001$ \\
\hline $\begin{array}{l}\text { A (Mitral inflow late } \\
\text { diastolic flow), } \mathrm{cm} / \mathrm{sn}\end{array}$ & $91 \pm 29$ & $81 \pm 22$ & $<0.001$ \\
\hline E/A mitral & $1.24 \pm 0.38$ & $0.96 \pm 0.27$ & $<0.001$ \\
\hline $\begin{array}{l}\mathrm{S} \text { (Pulmonary vein inflow } \\
\text { systolic flow), } \mathrm{cm} / \mathrm{sn}\end{array}$ & $63.6 \pm 10.8$ & $57.2 \pm 12.9$ & $<0.001$ \\
\hline $\begin{array}{l}\text { D (Pulmonary vein inflow } \\
\text { diastolic flow), } \mathrm{cm} / \mathrm{sn}\end{array}$ & $56.0 \pm 12.1$ & $47.7 \pm 12.0$ & $<0.001$ \\
\hline $\mathrm{S} / \mathrm{D}$ & $1.17 \pm 0.26$ & $1.26 \pm 0.41$ & 0.027 \\
\hline Sm (lateral mitral annulus), $\mathrm{cm} / \mathrm{sn}$ & $10.9 \pm 2.9$ & $11.4 \pm 3.5$ & 0.31 \\
\hline Em (lateral mitral annulus), $\mathrm{cm} / \mathrm{sn}$ & $10.7 \pm 2.9$ & $10.9 \pm 2.8$ & 0.43 \\
\hline Am (lateral mitral annulus), $\mathrm{cm} / \mathrm{sn}$ & $9.3 \pm 2.0$ & $8.5 \pm 1.9$ & $<0.001$ \\
\hline $\mathrm{Em} / \mathrm{Am}$, lateral & $1.19 \pm 0.54$ & $1.23 \pm 0.52$ & 0.14 \\
\hline Mitral inflow E/Em lateral (E/Em) & $13.8 \pm 5.1$ & $11.4 \pm 4.4$ & $<0.001$ \\
\hline Sm (septal mitral annulus), $\mathrm{cm} / \mathrm{sn}$ & $8.6 \pm 1.9$ & $8.7 \pm 2.0$ & 0.50 \\
\hline Em (septal mitral annulus), $\mathrm{cm} / \mathrm{sn}$ & $8.5 \pm 2.7$ & $7.1 \pm 2.4$ & $<0.001$ \\
\hline Am (septal mitral annulus), $\mathrm{cm} / \mathrm{sn}$ & $9.3 \pm 2.0$ & $8.5 \pm 1.9$ & $<0.001$ \\
\hline Em/Am, septal & $0.94 \pm 0.34$ & $0.89 \pm 0.33$ & 0.12 \\
\hline Mitral inflow E/Em septal (E/Em) & $13.9 \pm 5.1$ & $11.4 \pm 4.4$ & $<0.001$ \\
\hline \multicolumn{4}{|c|}{$\begin{array}{l}\text { HD: haemodialysis; ESRD: end-stage renal disease; TDI: Tissue Doppler imaging; } \\
\text { E/A: ratio of E to A diastolic mitral inflow rates; S/D: ratio of S to D pulmonary venous } \\
\text { inflow rate; Sm: myocardial peak systolic velocity; Em: tissue Doppler imaging early } \\
\text { diastolic mitral annular velocities; Am: tissue Doppler imaging late diastolic mitral } \\
\text { annular velocity; Em/Am: ratio of Em to Am; E/Em: ratio of early mitral inflow rate to } \\
\text { early TDI diastolic mitral annuler rate }\end{array}$} \\
\hline
\end{tabular}

TABLE 4. Multiple linear regression analysis between echocardiographic $\mathrm{Em} / \mathrm{Am}$ ratio and clinical and laboratory parameters

\begin{tabular}{lccc}
\hline & $\mathrm{t}$ & $95 \% \mathrm{CI}$ & $\mathrm{p}$ value \\
\hline Age (years) & 1.7 & $-5.4-5.3$ & 0.1 \\
Gender (male) & -1.6 & $-0.3-0.04$ & 0.1 \\
Body mass index $(\mathrm{kg})$ & 0.4 & $-0.02-0.03$ & 0.7 \\
Mean blood pressure (mmHg) & -0.3 & $-0.004-0.003$ & 0.8 \\
Heart rate (beats/min) & 0.17 & $-0.007-0.008$ & 0.9 \\
Creatinine (mg/dL) & 0.3 & $-0.04-0.05$ & 0.7 \\
Serum sodium (mEq/L) & 0.5 & $-0.03-0.05$ & 0.6 \\
Serum potassium $(\mathrm{mEq} / \mathrm{L})$ & -0.8 & $-0.16-0.07$ & 0.5 \\
Ultrafiltration volume $(\mathrm{mL})$ & -1 & $0-0$ & 0.3 \\
\hline CI: confidence interval & & &
\end{tabular}

CI: confidence interval

remained statistically unchanged. This is because both endsystolic and end-diastolic diameters diminished following HD. Second, we showed that a single HD therapy was related to acute deterioration in diastolic parameters as examined by conventional Doppler ECHO. Both mitral inflow E and A velocities declined after $\mathrm{HD}$ treatment. Because $\mathrm{E}$ velocity decreased more than A velocity, the ratio of E/A diminished 
as well. A similar condition was endorsed for the pulmonary vein inflow $\mathrm{S}$ and $\mathrm{D}$ parameters. Thus, these parameters indicated the volume dependent index for evaluating diastolic functions. Third, our results implied that the Em/Am ratio, as calculated by TDI, was a relatively load-independent index of diastolic function in HD patients. Both Em and Am velocities decreased significantly after a single HD session. Due to a similar reduction in Em and Am velocities, the Em/Am ratio did not change significantly. Peak E transmitral flow rates / peak $\mathrm{E}$ diastolic myocardial rates $(\mathrm{E} / \mathrm{Em})$, the other parameter evaluated for myocardial function, decreased significantly after HD due to a more pronounced decrease in mitral inflow E.

Galetta et al. (16) previously reported that a single HD session is related to acute systolic and diastolic myocardial dysfunctions, as evaluated by TDI. It was also suggested that low interdialytic weight gain and ultrafiltration volume are cardioprotective factors in this patient group. Mendes et al. (17) reported that pulsed TDI, colour TDI, and speckle tracking imaging provided similar outcomes for the calculation of $\mathrm{S}$ and $\mathrm{D}$ myocardial operation in clinically stable patients with ESRD on HD for more than 4 months. Interestingly, Drighil and colleagues (11) suggested that systolic and diastolic venticular TDI velocities are load-dependent, and that potent HD treatment may provide insight into determining the onset of diastolic dysfunction in adolescent ESRD patients. Additionally, Fijalkowski et al. (14) suggested that mitral annular TDI velocity may offer an optional worthwhile preload-independent marker for evaluating LV D impairment in ESRD.

The early rapid filling of LV during diastole (E) depends on volume status. A compensatory increase in the late atrial phase of LV filling (A wave) occurs in patients with impaired LV compliance or abnormal relaxation, which results in a reduced $\mathrm{E} / \mathrm{A}$ ratio. This situation is designated "impaired relaxation", considering the diastolic dysfunction diagnosis (18). Our ECHO data confirm the presence of HD-induced diastolic dysfunction in ESRD patients. Of interest, Zaslavsky et al. (19) previously reported impaired diastolic function as an important prognostic mortality indicator for ESRD patients on initial dialysis treatment.

In HD patients, hypervolemia may disguise the LV diastolic and systolic dysfunction (8). Because of this, the frequency and severity of LV dysfunction may be grossly underestimated. Therefore, parameters with low sensitivity to loading conditions (load-independent) are clinically relevant $(11,16,17)$. Our current findings suggest that the $\mathrm{Em} / \mathrm{Am}$ ratio determined from HD patients using TDI may serve as a relatively loadindependent predictor of diastolic function. Therefore, TDI determination of the Em/Am ratio may be a more accurate method of identifying diastolic dysfunction when the evaluation is performed for ESRD patients on HD.

There are several limitations that must be discussed when interpreting our results. Our experimental findings are predominantly observational, with evaluations that were asso- ciative and not predictive or causative. Furthermore, we did not perform any routine follow-up of the patients studied. Our study was performed on a relatively small population $(n=58)$, but still large in comparison to previous studies in the field. For ethical reasons, we did not keep the total fluid volume removed constant, so the quantity of dialytic fluid removed was not controlled. Finally, in compliance with previous studies $(11,17)$, the ECHO and TDI variables were given for the pre- or post-HD conditions. Our future research will be aimed at clarifying whether these changes in the ECHO and TDI parameters have prognostic implications for HD patients.

In conclusion, the present study shows an immediate association between HD and deterioration in the diastolic parameters. Since the $\mathrm{Em} / \mathrm{Am}$ ratio remained unchanged following $\mathrm{HD}$, we propose the use of the $\mathrm{Em} / \mathrm{Am}$ ratio as a relatively load-independent index of diastolic function in ESRD patients.

As numerous detrimental effects of renal insufficiency on cardiac function begin well before the need for HD, an evaluation of cardiac functions before the patient reaches ESRD is paramount.

Ethics Committee Approval: Ethics committee approval was received for this study from the ethics committee of the Faculty of Medicine of Uludag University.

Informed Consent: Written informed consent was obtained from patients who participated in this study.

Peer-review: Externally peer-reviewed.

Author contributions: Concept - D.Y., S.S., K.D.; Design - D.Y., S.S., K.D.; Supervision - A.A.; Resource - A.Y., K.D.; Materials - A.Y., K.D., D.Y.; Data Collection\&/or Processing - S.S., D.Y.; Analysis\&/or Interpretation D.Y., O.A.S., A.A.; Literature Search - S.S., D.Y.; Writing - S.S., D.Y., T.S.; Critical Reviews - A.A, K.D.

Conflict of Interest: No conflict of interest was declared by the authors.

Financial Disclosure: The authors declared that this study has received no financial support.

\section{REFERENCES}

1. Collins AJ, Foley RN, Gilbertson DT, Chen SC. The state of chronic kidney disease, ESRD, and morbidity and mortality in the first year of dialysis. Clin J Am Soc Nephrol 2009;4(Suppl 1):S5-11. [CrossRef]

2. Bradbury BD, Fissell RB, Albert JM, Anthony MS, Critchlow CW, Pisoni RL, et al. Predictors of early mortality among incident US hemodialysis patients in the Dialysis Outcomes and Practice Patterns Study (DOPPS). Clin J Am Soc Nephrol 2007;2:89-99. [CrossRef]

3. Sahinarslan A, Güz G, Mutluay R, Okyay K, Demirtaş C, Paşaoğlu H, et al. The impact of dialysis type on biomarkers for cardiovascular diseases. Turk Kardiyol Dern Ars 2011;39:456-62. [CrossRef]

4. Ritz E, Bommer J. Cardiovascular problems on hemodialysis: Current deficits and potential improvement. Clin J Am Soc Nephrol 2009;4(Suppl 1):S71-8. [CrossRef] 
5. Sniderman AD, Solhpour A, Alam A, Williams K, Sloand JA. Cardiovascular death in dialysis patients: Lessons we can learn from AURORA. Clin J Am Soc Nephrol 2010;5:335-40. [CrossRef]

6. Wright J, Hutchison A. Cardiovascular disease in patients with chronic kidney disease. Vasc Health Risk Manag 2009;5:713-22.

7. Sułowicz W, Radziszewski A. Dialysis induced hypotension--a serious clinical problem in renal replacement therapy. Med Pregl 2007;60(Suppl 2):14-20.

8. Selby NM, McIntyre CW. The acute cardiac effects of dialysis. Semin Dial 2007;20:220-8. [CrossRef]

9. McIntyre CW. Haemodialysis-induced myocardial stunning in chronic kidney disease - a new aspect of cardiovascular disease. Blood Purif 2010;29:105-10. [CrossRef]

10. Voroneanu L, Covic A. Arrhythmias in hemodialysis patients. J Nephrol 2009;22:716-25.

11. Drighil A, Madias JE, Mathewson JW, El Mosalami H, El Badaoui N, Ramdani B, et al. Haemodialysis: Effects of acute decrease in preload on tissue Doppler imaging indices of systolic and diastolic function of the left and right ventricles. Eur J Echocardiogr 2008;9:530-5. [CrossRef]

12. Civilibal M, Caliskan S, Oflaz H, Sever L, Candan C, Canpolat N, et al. Left ventricular function by 'conventional' and 'tissue Doppler' echocardiography in paediatric dialysis patients. Nephrology (Carlton) 2009;14:636-42. [CrossRef]

13. Akkaya M, Erdoğan E, Sağ S, Arı H, Türker Y, Yılmaz M. The effect of hemodialysis on right ventricular functions in patients with end-stage renal failure. Anadolu Kardiyol Derg 2012;12:5-10.
14. Fijalkowski M, Koprowski A, Gruchala M, Galaska R, Debska-Slizien A, Rogowski J, et al. Effect of preload reduction by hemodialysis on myocardial ultrasonic characterization, left atrial volume, and Doppler tissue imaging in patients with end-stage renal disease. J Am Soc Echocardiogr 2006;19:1359-64. [CrossRef]

15. Lang RM, Bierig M, Devereux RB, Flachskampf FA, Foster E, Pellikka $\mathrm{PA}$, et al. Recommendations for chamber quantification: A report from the American Society of Echocardiography's Guidelines and Standards Committee and the Chamber Quantification Writing Group, developed in conjunction with the European Association of Echocardiography, a branch of the European Society of Cardiology. J Am Soc Echocardiogr 2005;18:1440-63. [CrossRef]

16. Galetta F, Cupisti A, Franzoni F, Carpi A, Barsotti G, Santoro G. Acute effects of hemodialysis on left ventricular function evaluated by tissue Doppler imaging. Biomed Pharmacother 2006;60:66-70. [CrossRef]

17. Mendes L, Ribeiras R, Adragão T, Lima S, Horta E, Reis C, et al. Loadindependent parameters of diastolic and systolic function by speckle tracking and tissue doppler in hemodialysis patients. Rev Port Cardiol 2008;27:1011-25.

18. Ie EH, Zietse R. Evaluation of cardiac function in the dialysis patient-a primer for the non-expert. Nephrol Dial Transplant 2006;21:1474-81. [CrossRef]

19. Zaslavsky LM, Pinotti AF, Gross JL. Diastolic dysfunction and mortality in diabetic patients on hemodialysis: a 4.25-year controlled prospective study. J Diabetes Complications 2005;19:194-200. [CrossRef] 